\title{
LOWER FAMENNIAN ORGANOGENIC DEPOSITS IDENTIFIED, CORRELATED AND CLASSIFIED WITHIN THE PRIPYAT TROUGH

\author{
S.V. Antipenko
}

\section{ВЫДЕЛЕНИЕ, КОРРЕЛЯЦИЯ И КЛАССИФИКАЦИЯ ОРГАНОГЕННЫХ ОТЛОЖЕНИЙ НИЖНЕГО ФАМЕНА ПРИПЯТСКОГО ПРОГИБА \\ С.В. Антипенко}

The suggested classification of organogenic deposits of the Lower Famennian in the Pripyat Trough was developed on the grounds of available classifications and data of geological (lithologic, palaeontological, palaeoecological) investigations carried out in the region. This classification provides an opportunity to identify unambiguously and to correlate these genetically similar deposits, their groups, types and kinds (forms) widespread in many palaeobasins throughout the world, especially those promising for various mineral occurrences.

Key words: classification, organogenic deposits, organic mounds, groups, types, kinds, shape.

Предложенная классификация органогенных отложений нижнего фамена Припятского прогиба разработана на основе анализа имеющихся классификаций и материалов геологических (литологических, палеонтологических, палеоэкологических) исследований в регионе. Она предоставляет возможность однозначного выделения и корреляции этих генетически однородных отложений, их групп, типов и видов (форм), распространенных во многих палеобассейнах мира, в особенности, перспективных на поиск различных полезных ископаемых.

Ключевые слова: классификация, органогенные отложения, органогенные постройки, группы, типы, виды, формы.

При изучении органогенных отложений необходимо придерживаться четкой, научно обоснованной классификации этих образований. На протяжении последних 40 лет многие исследователи межсолевых нижнефаменских отложений Припятского прогиба по-разному трактовали происхождение, строение, наименование, размеры и геологическое значение встречающихся органогенных тел. Их разновидности авторы называли «органогенными банками», «пакетами», «рифами», «отмелями», «подводными лугами» и т.д. [11, 13, 15 и др.]. Наиболее значительный вклад в изучение отложений внесла обобщающаяся монография А.С. Махнача, В.А. Москвича, С.А. Кручека, И.И. Урьева «Органогенные постройки девона Белоруссии» [12], в которой большое внимание уделено органогенным фация нижнего фамена Припятского прогиба. Приведенная в данной работе типизация органогенных построек в целом соответствовала мировым представлениям о них исследователей на тот период и опиралась на разработанную российскими геологами классификацию $[4,6,7]$. Однако в ней и в многочисленных других публикациях [10, 18 и др.] допущены, на наш взгляд, существенные ошибки, во-первых, «органогенные отложения» отождествляются с «органогенными постройками», во-вторых, сами «органогенные постройки» часто не отделяются от довольно мощных карбонатных толщ хемогенного («иловых холмов», «куполов», «пластов» и др.) и биогенно-аккумулятивного (желваково-онколитовых, ракушечниковых и др.) генезиса, хорошо картируемых дистанционными методами, в-третьих, во многих случаях неверно интерпретируется роль отдельных организмов в создании этих тел. Такие противоречивые подходы к изучению одних и тех же отложений несомненно вносят путаницу в терминологию, понимание условий происхождения (генезиса) разнородных толщ, возможностей их формирования различными группами организмов и, в конечном счете, в выявление и корреляцию перспективных на полезные ископаемые геологических тел.

Следует подчеркнуть, что большинство работ по органогенными постройкам (являющимся составной частью органогенных отложений) и отложениям, содержащим органику вообще, характеризуют толщи, исследованные в обнажениях коренных пород [4, 6-10, 18]. Так, например, в работе В.Г. Кузнецова «Палеозойское рифообразование на территории России и смежных стран» [10] рассматривается классификация рифов (построек) с двух позиций - по их геоморфологической приуроченности и функциональному характеру рифостроителей. При этом, автор указывает «... может быть несколько классификаций одного объекта, и каждая из них, если она построена без нарушения основных законов классифицирования, правомерна и применима для решения тех или иных задач» [10 с. 9]. В условиях Припятского прогиба, имея в наличии лишь керновый материал девонских разрезов 
скважин, конкретно можно изучать только состав органических остатков и формы их залегания в породах отложений, т.е. достоверно классифицировать их по функциональным возможностям породообразующих организмов. Уверенное же пространственное их прослеживание практически невозможно, его можно лишь предполагать на основе общих структурных построений и гипотетической реконструкции рельефа дна палеобассейна седиментации на отдельных участках.

Опираясь на знание тектонического развития прогиба, детальное стратиграфическое расчленение разрезов и их корреляцию, а также имея достаточный опыт в литологическом и палеонтологическом изучении карбонатных осадочных толщ, содержащих основные породообразующие организмы межсолевых отложений - известковые цианобактерии и водоросли (до 95\%) [1-3 и др.], нам представляется возможным впервые предложить схему классификации нижнефаменских органогенных отложений Припятского прогиба (рисунок), в основу которой положены ранее разработанные классификации (типизации) И.К. Королюк, М.В. Михайловой [7, 8], И.Т. Журавлевой, Е.И. Мягковой [6], Н.М. Задорожной [4] и других исследователей. Проведенный анализ этих классификаций (типизаций) позволил выявить неоднозначные подходы авторов к выделению органогенных тел. В них так и не определены ранг, название и соотношение основных классификационных единиц - органогенноаккумулятивных отложений и органогенных построек, которые, безусловно, следует выделить в отдельные равноправные группы отложений. Непонятна также, иерархическая принадлежность элементарных, простых, сложных и сложно-дифференцированных органогенных построек, отнесенных к типам (?), которые в свою очередь, разделяются на более дробные «типы» (?) - калиптры, биогермы, биостромы, их массивы, рифы и рифоиды $[4,7,8]$.

Нам представляется целесообразным отнести к «типам» - непосредственно-элементарные, простые, сложные и сложно-дифференцированные постройки, так как понятия, заложенные в самих их названиях, характеризуют именно общий тип сложности строения органогенного тела, постройки, а калиптры, биогермы, биостромы, их массивы, рифы и рифоиды, входящие в их состав, выделенные ранее, в основном по морфологическим признакам, в дальнейшем следует относить к «видам (формам)» этих тел. Отметим, что в предложенную схему нами намеренно не включены типы сложных и сложно-дифференцированных органогенных построек $[4,7,12]$, достоверно выделить которые в межсолевых отложениях Припятского прогиба не удалось. В состав же простых органогенных построек нами включены строматолиты - своеобразные по форме, исключительно каркасные органогенные постройки [2, 3].

Органогенные отложения - это литологические разности пород, образованные организмами или сложенные их остатками на месте прижизненного обитания, т.е. имеющие органическое происхождение (генезис). На участках существования бывших подводных биоценозов часто в массовом количестве отлагались отмершие органические остатки (тафоценозы), состоящие из групп, прикрепленных или неприкрепленных ко дну при жизни известковых, кремниевых и др. скелетов организмов. Скопления неприкрепленных органических остатков - желваков, ракушечника, детрита, представляют собой типичные аккумулятивные толщи пассивного заполнения органикой (бентосной, нектонной, планктонной). Если же организмы вели прикрепленный к твердому субстрату образ жизни, то они создавали различные формы наростов на дне и являлись активными строителями жестких каркасов органогенных построек [1-3, 9]. Именно это принципиальное различие в механизме формирования отложений не учитывается или даже отрицается многими исследователями, относящими, например, аккумулятивные желваковые (онколовые) толщи, непосредственно к органогенным постройкам - «онколитовым банкам», «онколитовым рифам», «бескаркасным рифам» и т.д. [10, 11, 13 и др.], или частично учитывается при отнесении их к «карбонатным телам морфологически сходным с ископаемыми органогенными постройками» [4, 12]. В связи с этим, целесообразно выделить аккумулятивные органогенные отложения в отдельную группу, наравне с органогенными постройками, в составе органогенных отложений. Такое решение, на наш взгляд, внесет определенную однозначность в понимание иерархической принадлежности этих двух групп органогенных отложений. При этом будут также соблюдены два основных требования к классифицированию - разделяемый объект («органогенные отложения») будет полностью представлен (охарактеризован) составляющими его членами («органогенно-аккумулятивными отложениями» и «органогенными постройками»), которые выделены по общим признакам. Нужно отметить, что наличие этих двух групп отложений всегда признавалось практически всеми исследователями, но ими не проводилось их конкретное выделение, обоснование и введение в классификацию именно «органогенных отложений». 
Ниже мы остановимся непосредственно на краткой характеристике групп, типов и видов (форм) органогенных отложений, имеющихся в нижнем фамене Припятского прогиба, с приведением их геоморфологических особенностей, подробно описанных в геологической литературе [4, 7, 10, 12 и др.].

Таким образом, все органогенные отложения делятся на две группы: органогенно-аккумулятивных отложений и органогенных построек.

Группа: Органогенно-аккумулятивные отложения - представлены литологическими телами, образованными скоплениями неприкрепленных ко дну при жизни остатков организмов, пассивно заполнявших осадочные толщи на месте обитания (in situ). Тела синхронно залегают с окружающими, часто слоистыми осадками или незначительно возвышаются над ними. В нижнефаменской межсолевой толще Припятского прогиба отложения представлены отдельными пластами, слоями, прослоями, линзами или многоярусными биоритмичными толщами их. Встречаются три основных типа отложений - желваковые, ракушечниковые и детритовые.

Тип: Желваково-аккумулятивные отложения - представлены литологическими толщами, заполненными желваками (онколитами) размером от 1-2 мм до 4-7 см, слагающими от 20 до 90\% объема вмещающих пород, образованными в основном известковыми цианобактериями, концентрически обраставшими твердые неприкрепленные подвижные объекты (раковины, детрит, песчинки и др.) на дне максимально мелководных участков бассейна с активной гидродинамической средой [1-3, 9]. Желваковые отложения содержатся в бугристонаслоенных пластах, линзах, куполах, мощностью от 2-10 см до 10-12 м. Часто они образовывали многоярусные биоритмитные толщи переслаивания с более глинистыми осадками, мощностью от 1-3 до 100-200 м. В нижнефаменских отложениях Припятского прогиба это основные (до 80-90\%) и самые распространенные органогенные образования $[1-3,5,15]$. Они встречаются в мелководных фациях практически всего разреза межсолевой толщи, во всех краевых зонах прогиба.

Тип: Ракушечниково-аккумулятивные отложения - представлены маломощными (от 1-3 до 20-60 см) прослоями, пластами, линзами, заполненными в основном цельнораковинными скоплениями отмерших организмов - брахиопод, моллюсков (гастропод, пелеципод, аммоноидей, бактритоидей), ракообразных (остракод), иглокожих (криноидей), составляющими от 10 до 90\% объема вмещающих пород. Отложения фрагментарно встречаются в разрезах межсолевой толщи, преимущественно в северной и западной частях прогиба $[5,12,14,15]$.

Тип: Детритово-аккумулятивные отложения - представлены маломощными (от 1-3 см до 40 см) скоплениями органики в пластах, линзах и полостях, состоящих из разнообломочного (чаще-мелкообломочного) органического детрита, сплошного или разреженного, и мелкой цельнораковинной фауны - брахиопод, моллюсков, ракообразных, иглокожих, фораминифер, радиолярий, известковых водорослей (зеленых, харовых) и растительных остатков. Детрит заполняет от 5-10 до 50-60\% объема вмещающих пород. Отложения фрагментарно встречаются в разрезах всех краевых зон Припятского прогиба $[2,3,5,15]$.

Эти три типа отложений часто имеют смешанный, взаимопереходящий состав органических остатков, к которым нельзя относить явно переотложенные включения пород, наблюдаемые в брекчиях различного генезиса.

Группа: Органогенные постройки - представлены компактными литологическими телами, образованными в первую очередь активно прикреплявшимися к твердому субстрату дна каркасообразующими сообществами организмов-строителей, цементаторов и улавливателей [17], совместно с комплексом остатков сопутствующей неприклепленной органики - пассивных межкаркасных заполнителей («рифолюбов», «сателлитов»). Постройки формировались (литифицировались) опережающими темпами по сравнению с одновозрастными окружающими их, часто слоистыми, более глинистыми осадками, за счет чего обычно значительно возвышались над ними в виде холмов, бугров куполов, иногда изометричной формы. По сложности строения и размерам органогенные постройки делятся на несколько типов $[4,6,7,10,12]$. В межсолевых отложениях Припятского прогиба представлены двумя типами - элементарными и простыми органогенными постройками [1-3].

Тип: Элементарные органогенные постройки - представлены мелкими (до 20-40 см) литологическими телами, созданными одним или несколькими каркасными и сопутствующими организмами. Они, по-видимому, являются кратковременными зачаточными или угнетенными формами неразвившихся более крупных, массивных построек - биогермов и биостромов. Их скорость роста практиче- 
ски не опережала темпы отложения окружающих синхронных глинистых осадков, с которыми они также часто ритмично переслаивались. В межсолевых отложениях прогиба представлены одним видом (формой) построек - калиптрами [1-4, 12].

Вид (форма): Калиптры (Caliptra - греч. «шапочка») - мелкие ( от 2-3 до 10-30 см), сферические, линзовидные, бугристонаслоенные литологические тела сложенные каркасными и неприкрепленными организмами. Каркасообразующие организмы составляют от 30 до 60\% объема вмещающих пород. В межсолевых отложениях прогиба они представлены желваковыми и корковыми наростами красных (багряных) известковых водорослей, иногда совместно с пластинчатыми строматопоратами (кишечнополостными) и мшанками. Сопутствующая бентосная органика обычно представлена немногочисленными остатками брахиопод, моллюсков, иглокожих, ракообразных, сифоней, харофитов. В некоторых разрезах отмечается биоритмичное переслаивание, мощностью от 0,5 до 8-10 м, представляющее бугристое чередование глинистых и карбонатных прослоев, содержащих разнообломочный раковинный детрит, что свидетельствует о непостоянности гидродинамических условий на этих мелководных участках палеобассейна [2,3]. Калиптры часто встречаются в разрезах северной и западной частей Припятского прогиба.

Тип: Простые органогенные постройки - представлены компактными, часто довольно массивными литологическими телами, мощностью, обычно, от 0,5 до 20 м и более, образованными преимущественно активными каркасообразующими сообществами организмов (строителей, цементаторов, улавливателей), совместно с комплексом остатков неприкреплявшихся организмов - заполнителей. Тела построек формировались быстрыми темпами, за счет чего они значительно или круто возвышались над окружающими синхронными осадками, иногда даже нависали над ними краями. По форме, размерам и составу организмов простые органогенные постройки ранее были разделены на биогермы и биостромы $[4,7,8,12]$, к которым мы также отнесли строматолиты - самостоятельные, исключительно каркасные формы построек [1-3, 9]. Данные виды (формы) построек довольно широко распространены в отложениях мелководных фаций межсолевого комплекса северной и западной краевых зон Припятского прогиба.

Вид (форма): Строматолиты (stroma - греч. «постель, ложе», litos - «камень») - исключительно каркасные органогенные постройки разнообразных форм и размеров, образованные последовательно многослойно нарастающими вверх цианобактериальными микрокорочками (матами), прикрепившимися к твердому субстрату дна. В зависимости от рельефа поверхности субстрата, подвижности вод, привноса кластогенного материала и других факторов, строматолитовые наросты приобретали различные формы: пластовые (корковые), столбчатые, ветвистые, желваковые (облаковидные) и другие [1-3, 9]. Размеры имеющихся в отложениях прогиба строматолитов изменяются от 3-5 до 120 см. В некоторых разрезах отмечается наличие нескольких биоритмичных уровней со строматолитами, мощностью от 0,3 до 15 м. Характерна приуроченность их к отложениям III, V, VII литологических пачек межсолевого комплекса Припясткого прогиба, отличающихся высокой глинистостью разрезов (региональных флюидоупоров), нередко их осульфаченностью, а также отсутствием других органических остатков в этой экологической нише.

Вид (форма): Биогермы (bio - греч. «жизнь», herma - «холм») - массивные органогенные постройки, имеющие округлую, куполовидную, холмовидную, грибовидную и др., часто изометричные формы. Размеры их обычно варьируют от 0,5 до 10 м, реже до 15-20 м (в поперечнике и по мощности), в межсолевых отложениях прогиба не превышают - 3 м, но иногда многоярусные биоритмитные толщи, включающие биогермы достигают 60-80 м. Постройки имеют жесткий прикрепленный органический каркас, составляющий от 20-30 до 60-80\% и более объема породы, созданный желваковыми и корковыми наростами красных (багряных) известковых водорослей, иногда совместно с пластинчатыми колониями строматопорат и мшанок, которые прикреплялись к твердому карбонатному субстрату и активно продуцировали, цементируя окружающий осадок и наращивая объем биогерма. Тело постройки формировалось (литицировалось) быстро, значительно опережая отложение окружающих осадков. Организмы - сателлиты, обитавшие в составе прижизненного биоценоза биогерма, представлены брахиоподами, гастроподами, остракодами, криноидеями, зелеными (сифонеями) и харовыми (умбеллацеями) известковыми водорослями, детрит которых преимущественно мелкий, отсортированный, что указывает на относительную удаленность этих построек от максимально мелководных участков - источников сноса. Биогермы явля- 
ются самыми распространенными формами (видами) органогенных построек в межсолевых отложениях, приуроченными к мелководным фациям северной и западной краевых зон Припятского прогиба [1-3].

Вид (форма): Биостромы (bio - греч. «жизнь», stroma - «ложе») - массивные или слоистые органогенные постройки, имеющие пластообразную или линзовидную форму, образованные каркасообразующими и сопутствующими организмами. Мощность их обычно варьирует от 0,5-2 до 20 м, а по площади они могут распространяться в разных направлениях от нескольких метров до десятков километров [4,7]. В отложениях межсолевого комплекса Припятского прогиба выделение их весьма проблематично, вследствие ограниченности прослеживания площадной протяженности пластов даже на отдельных структурах. Однако проведенная корреляция близко расположенных разрезов на некоторых участках прогиба позволяет все же относить морфологически схожие, сопоставимые по мощности и одинаковые по составу органических остатков пласты, к биостромным постройкам мощностью от 0,8 до 2 м. Каркасообразующими организмами в них являются красные (багряные) известковые водоросли и строматопораты, слагающие от 20-30 до 40-50\% объема пород, сопутствующими - бентосные брахиоподы, гастроподы, остракоды, сифонеи и харофиты. Биостромы эпизодически встречаются в разрезах межсолевого комплекса, приуроченных к мелководным фациям северной и западной краевых зон Припятского прогиба [1-3].

Впервые приведенная классификация нижнефаменских межсолевых органогенных отложений Припятского прогиба несомненно послужит основой для дальнейшего однозначного и уверенного выделения и корреляции генетически однородных органогенных отложений, их групп, типов и видов (форм). Важность этой классификации заключается в самом объекте исследования - органогенных отложениях, являющихся реальными или потенциальными накопителями (ловушками, коллекторами) углеводородов. Многолетние исследования отложений в Припятском прогибе, проведенные автором, позволили проследить определенные закономерности их стратиграфического и пространственного распространения, что привело к выводу о приуроченности их именно к типу желваково-аккумулятивных отложений (II и IV - литопачек, задонского горизонта) и к видам (формам) - биогермов и биостромов (VI - литопачки, елецкого горизонта), основных пористо-кавернозных, часто встречающихся, высокоемкостных коллекторов (ловушек) Северного НГР Припятской НГО, а расположение строматолитовых построек в глинисто-карбонатных породах III, V и VII литопачек - наоборот, характерно для флюидоупоров (покрышек) всех краевых зон прогиба [2, 3, $5,11-13,15]$.

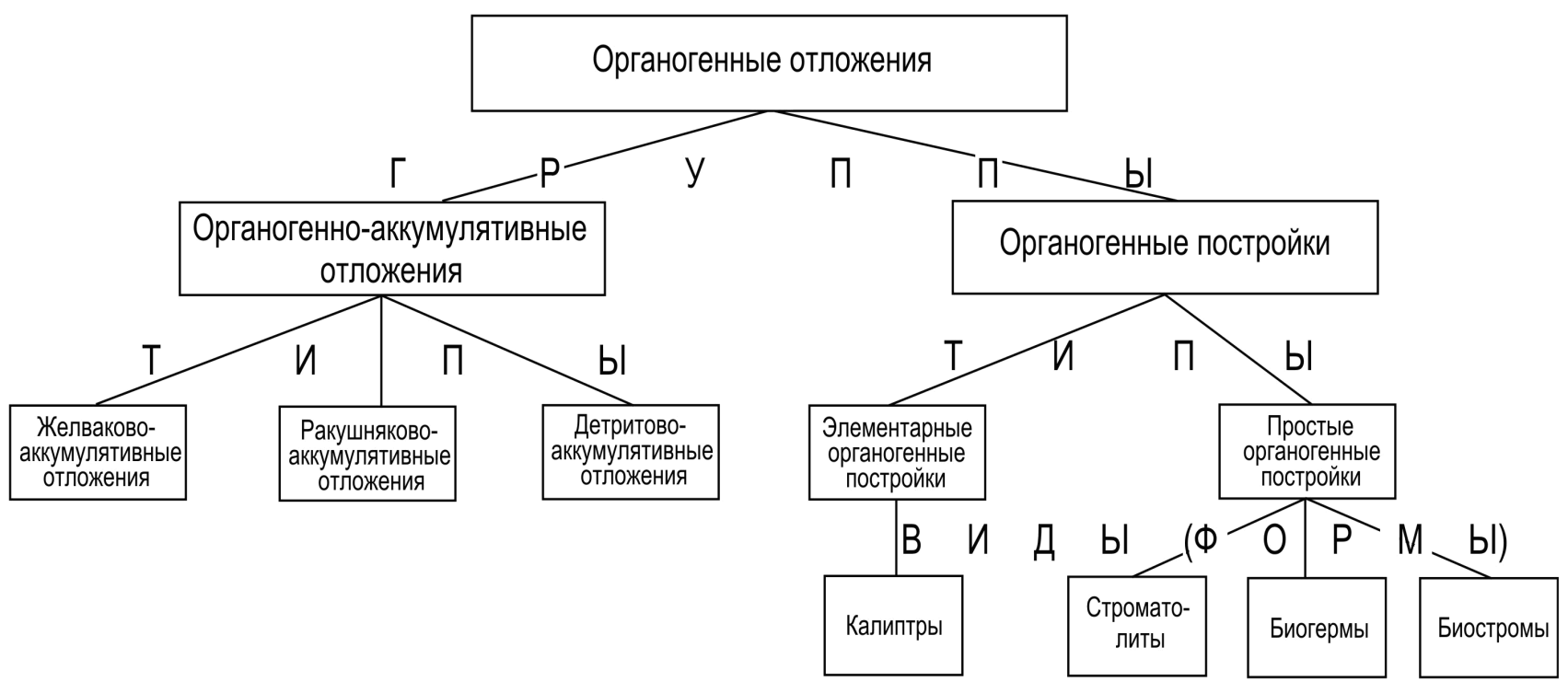

Рис. 1. Схема классификации органогенных отложений нижнего фамена Припятского прогиба 
1. Антипенко С.В. Биостратиграфические комплексы и сообщества известковых водорослей межсолевых (нижнефаменских) отложений Припятского прогиба // Геологическое строение и развитие платформенного чехла Белоруссии. - Минск: БелНИГРИ, 1992. С. 37-53.

2. Антипенко С.В. Роль известковых водорослей в формировании нижнефаменских органогенных образований Припятского прогиба // Палеоэкология и современное состояние геологической среды Беларуси. - Минск: БелНИГРИ, 1998. - С. 48-65.

3. Антипенко С.В. Распространение каркасообразующих известковых водорослей в нижнефаменских межсолевых отложениях Припятского прогиба // Стратиграфия и нефтеносность палеозойских отложений Беларуси. - Минск: БелНИГРИ, 2002. - С. 38- 50.

4. Геологическая съемка в районах развития отложений с органогенными постройками. Ленинград: Недра, 1982. - 328 c.

5. Девонская межсолевая толща Припятской впадины. Региональные закономерности строения и состава. Минск: Наука и техника, 1981 - 220 с.

6. Журавлева И.Т., Мягкова Е.И. О классификации современных и ископаемых органогенных построек // Среда и жизнь в геологическом прошлом. Вопросы экостратиграфии. Новосибирск: Наука, 1979. C. 117-128.

7. Ископаемые органогенные постройки, рифы, методы их изучения и нефтегазоносность. Москва: Наука, 1975. - $236 \mathrm{c}$.

8. Королюк И.К., Михайлова М.В. Сравнительная характеристика биогермных образований // Состояние и задачи советской литологии. - Москва: Наука, 1970. C. 229-235.
9. Крылов И.Н. Строматолиты рифея и фанерозоя СССР. - Москва: Наука, 1975. - 243 с.

10. Кузнецов В.Г. Палеозойское рифообразование на территории России и смежных стран. - Москва: ГЕОС, 2000. - $228 \mathrm{c.}$

11. Махнач А.С., Кручек С.А., Урьев И.И., Голубцов В.К. Об органогенных постройках в девонских отложениях Белоруссии // Доклады АН СССР, - 1975.Том 220. - № 4. С. 918-924.

12. Махнач А.С., Москвич В.А., Кручек С.А., Урьев И.И. Органогенные постройки девона Белоруссии. Минск: Наука и техника, 1984 - 236 с.

13. Москвич В.А. Основные типы органогенных построек задонско-елецких отложений верхнего девона и закономерности их распределения в Припятском прогибе // Ловушки нефти и газа Припятского прогиба (типы и прогноз). - Минск: Наука и техника, 1981. - С. 68-76.

14. Пушкин В.И., Демиденко Э.К., Некрята Н.С., Обуховская Т.Г. Опорный разрез нижнефаменских (межсолевых) отложений западной части Припятского прогиба // Доклады АН БССР, 1990. - Том 34. №12. C. $1111-1115$.

15. Пушкин В.И., Урьев И.И., Голубцов В.К. и др. Стратиграфия нижнефаменских (межсолевых) отложений Припятского прогиба. - Минск: ИГН, 1995. - 140 с.

16. Уилсон Дж. Л. Карбонатные фации в геологической истории. - Москва: Недра. 1980. - 463 с.

17. Fagerstrom J.A. The History of Devonian-Carboniferous Reef Communities: Extinctions, Effects, Recovery. // Facies, Erlangen, 1994.- Vol. 30. P. 177-192.

18. Nelson H.P., Brown G.W., Brineman J.H. Sceletal limestone classification. Amer. Assoc. Petrol. Geol., Mem. 1, 1962. - H. 224-252.

Republican Unitary Enterprise Belarusian Research Geological Exploration Institute, Minsk, Belarus Республиканское унитарное предприятие «Белорусский научно-исследовательский геологоразведочный институт», Минск, Беларусь 